\title{
Determination of Different Parameters to High Strength Steel Clinch Joints by FEA
}

\author{
Sz. JóNÁS ${ }^{1}, \mathrm{M}$. TISZA \\ ${ }^{1}$ Institute of Materials Science and Technology/Department of Mechanical Technology \\ E-mail: szabolcs.jonas@gmail.com \\ ${ }^{2}$ Institute of Materials Science and Technology/Department of Mechanical Technology \\ E-mail: miklos.tisza@uni-miskolc.hu
}

Abstract. In this article the clinched joints were analyzed by finite element method (FEA). The base materials were advanced high strength steels (DP 600, DP 800 and DP 1000). The model validation procedure was done by the DP 600 type of steel sheets; the other two types of steel were only simulated. The goal was to determine the geometrical properties of the joints with different strength steels. The FEA model was the same in every mechanical point of view therefore the results are comparable. The main geometrical parameters of the clinch joints are the neck thickness $\left(t_{N}\right)$, the undercut $(C)$, the bottom thickness $\left(t_{B}\right)$ and the height of the protrusion ( $h$ ); these values were compared.

\section{Introduction}

These joints are used mostly in automotive, computer and aircraft industries, but for instance according to the standards they are not allowed to be used in food industry [1]-[3]. The hardest goal is to use the lowest number of tests and use the articles and other available material and test data to determine the questioned parameters. The clinch joints are quite new types of joints, the first patent was accepted in 1989. This joint can be done between 2-3 thin sheet plates. The cross section of a joint can be seen in Figure 1, which shows the main geometrical parameters of a joint ( 2 sheets were joined).

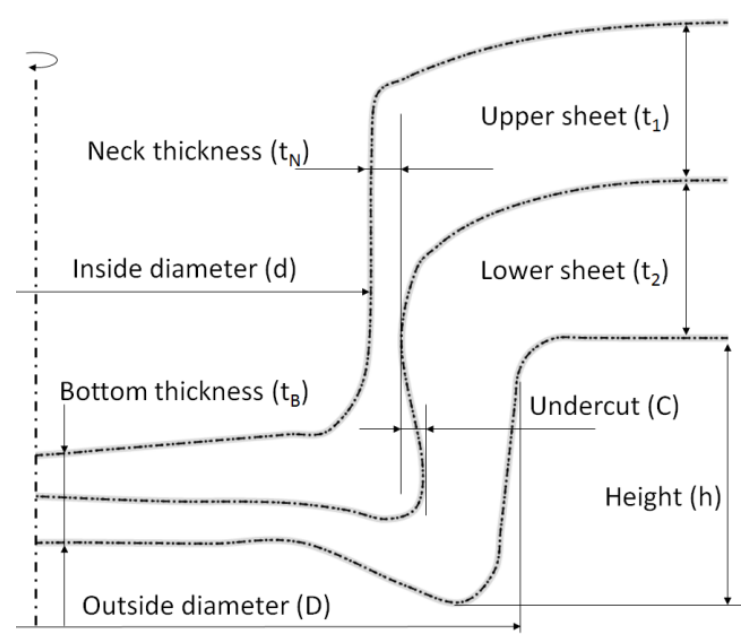

Figure 1. Cross section of a clinched joint and its main geometrical sizes 
The undercut size ( $\mathrm{C}$ value) and the neck thickness ( $\mathrm{t}_{\mathrm{N}}$ value) are highly affecting the strength of the joints. In optimal case both are as high as it possible. The material of the plates can be ferrous or nonferrous at the same time, so this joint can realize dissimilar joints without any added material (weld material or glue). The joint is made by metal plastic forming by a special tool. After creating the patent, the increasing industrial needs of these types of joints led the researchers to analyze the joints much more deeply. Several studies have been carried out concerning the geometry optimization of the clinching tool to achieve better joints by different optimization methods. Other studies were carried out on the so-called hybrid joints. These joints have an adhesive layer between the sheets. These joints have higher strength but they need much more time because the drying of the adhesive layer is a timeconsuming process [4][5].

\section{METHODS}

In this section the material and the FE model building and its validation for DP 600 is presented. Material properties were determined in the following article [6], the used values can be seen in Table 1.

Table 1. Results of the measurement [6]

\begin{tabular}{|l|c|c|c|c|c|c|}
\hline & UTS [MPa] & YS [MPa] & A80\% [\%] & $\varepsilon_{\text {crit. }}[\mathrm{mm} / \mathrm{mm}]$ & $\mathrm{K}[\mathrm{MPa}]$ & $\mathrm{n}[-]$ \\
\hline DP 600 & 656 & 445 & 13.6 & 0.124 & 918 & 0.112 \\
\hline DP 800 & 879 & 571 & 10.8 & 0.099 & 1217 & 0.104 \\
\hline DP 1000 & 1099 & 767 & 7.0 & 0.062 & 1481 & 0.083 \\
\hline
\end{tabular}

According to these values the flow curves can be seen in Figure 2. The curves are follows the Nádai hardening law (Eq. 1):

$$
\sigma=K \varphi^{n}
$$

where the $\mathrm{K}$ and $\mathrm{n}$ are material coefficients, the $\varphi$ is the equivalent plastic strain.

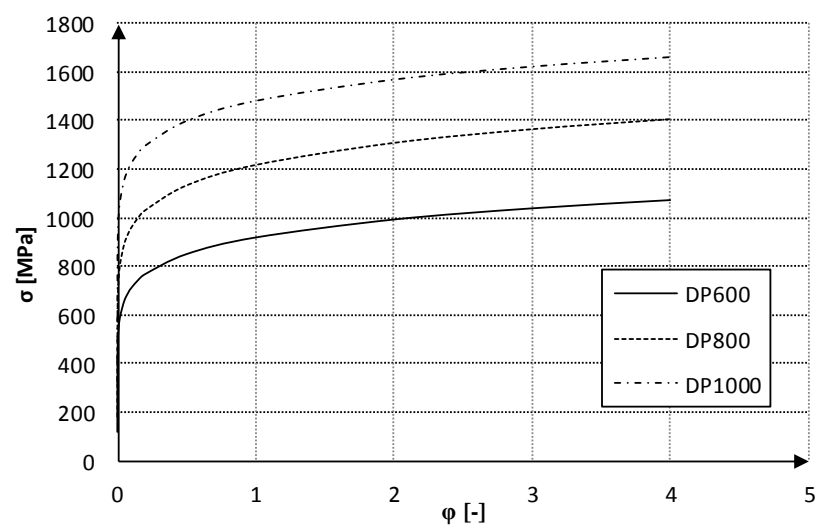

Figure 2. Extrapolated flow curves according to [6]

The FE simulation model was built in ANSYS WB 18.2 [7]. The geometry of the model was built up in ANSYS Design Modeller as a parametric model. A 2D axisymmetric model is presented below (Figure 3). The tools were taken into consideration as linear-elastic materials, the two sheets were simulated 
with elastic-plastic behaviour with multilinear isotropic hardening rule. The tool has a spring row which was taken into consideration as an elastic body with $57 \mathrm{GPa}$ of Young's modulus. The mesh was built up by 2nd order asymmetrical quadrilateral and triangular elements (PLANE183). Both of the sheets contain 10 elements in thickness which provides adequate results. For better solution the edges in the contact zones were finer. The contact definition between the parts is Augmented Lagrange formulation with a frictional coefficient $\mu=0.12$ between the parts. Between the punching tool and the simplified spring row the contact definition was bonded with MPC algorithm. The duration of the simulation is 3 time steps. The simulation is performed as a displacement-controlled model. According to the final, measured bottom thickness and the measured piston displacement, the vertical movement of the clinching tool was $3.25 \mathrm{~mm}$. The holder was constrained in vertical direction by a compression only support and in the 1st step a force $(\mathrm{F}=1000 \mathrm{~N})$ was applied which is constant in the 2nd and 3rd steps. In the 3rd step the tool was removed from the joint. The last step is important to analyse the effect of the spring back, which can be important in some forming cases. The distribution of the equivalent plastic strain was checked with the unaveraged display option, because if it is not continuous, then the results are unacceptable in the point of view of nonlinear calculations. The unaveraged distribution of the plastic strain can be seen in Figure 4. The high (greater than 2) plastic strains are acceptable, according to the literature [10].

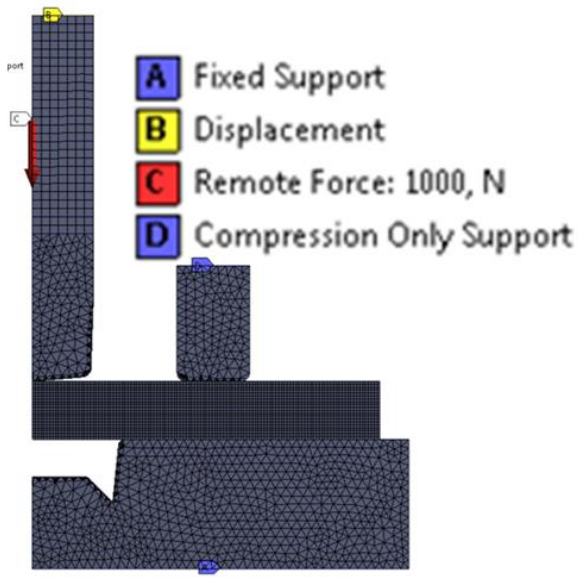

Figure 3. FE mesh and boundary conditions of the model

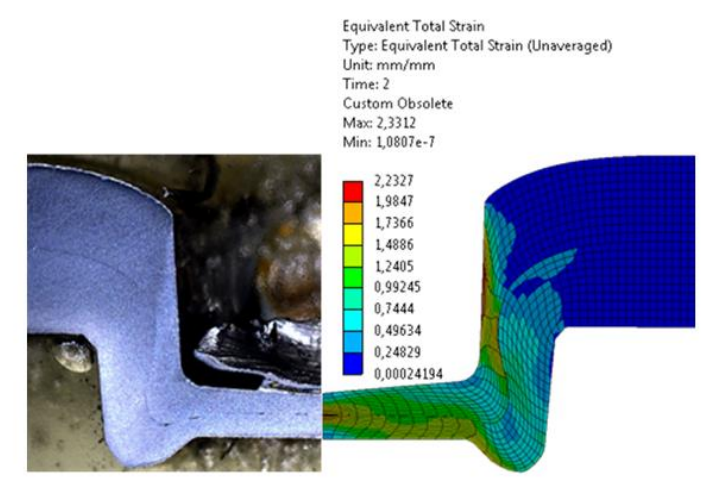

Figure 4. Equivalent plastic strain distribution after forming process (unaveraged) compare to the measurement

According to [8] the measured curve can be divided into 3 main phases and 5 steps. In Phase I. the testing machine starts to work, the punching tool moves down, the holder moves downward to fix the sheets, the tool comes into contact with the upper sheet (punch side) and the joining process is started (Step I.). The tool punches the sheets and they move together (Step I. - Step II.) and this part of the process continues until the first bending point (Step II.). The lower sheet (die side) reaches the die; that is why the slope of the curve changes after Phase I. In Phase II. the sheets start to flow around the punching tool and start to flow inside the free space of the die (Step III.). The last part of the process needs more deformation force; the curve rises with the highest slope. In Step IV. the punching tool reaches the end position. In this phase the setting force reaches the maximum also. After this point the 
tool starts to remove from the joint with a certain slope depending on the stiffness of the machine. After Step V. the joint is totally released. Severe plastic deformation occurs during the forming process (Step III. according to Figure 5). As already stated, true plastic strains of the order of 2-3 are not unusual and stress-strain data far beyond the maximum uniform strain have to be available for the analysis [9]-[10].

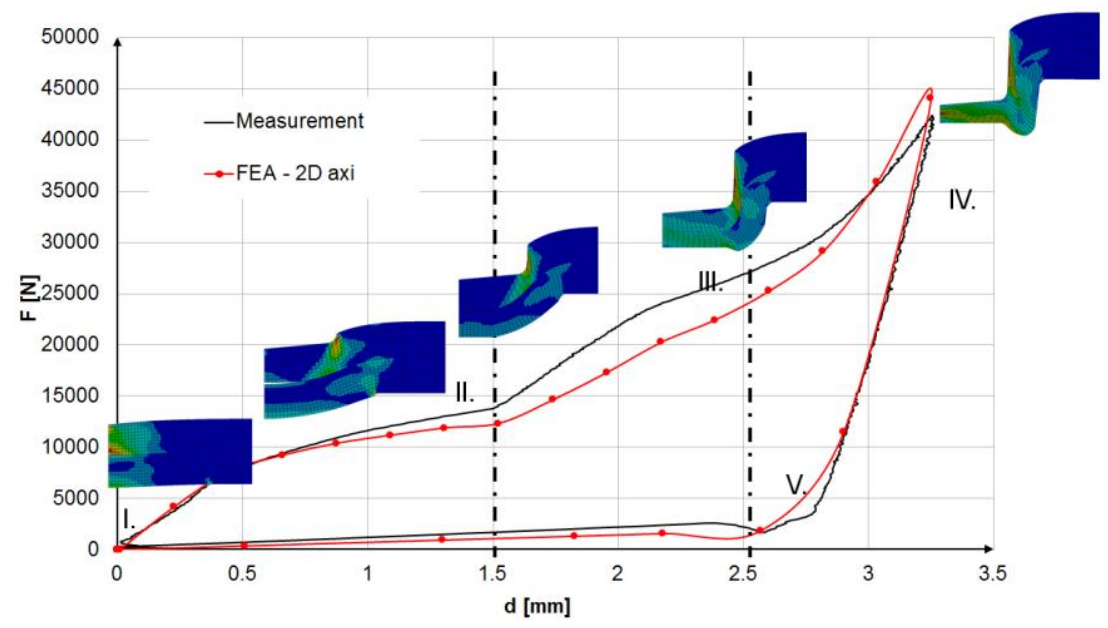

Figure 5. Comparison of the measured and simulated forming force-relative punching tool displacements

\section{RESULTS}

After the simulation of the three different DP steels the results were analysed and compared to each other. As it can be seen in the Figure 6 the forming force is increasing to the effect of the increasing strength. The displacement is equal in each case. The difference between the DP 600 and the DP 1000 is around $10 \mathrm{kN}$ in forming force. This observation is important because of the point of view of the clinching tool's load bearing capacity. Before testing, a fast prediction can be save the tool against failure.

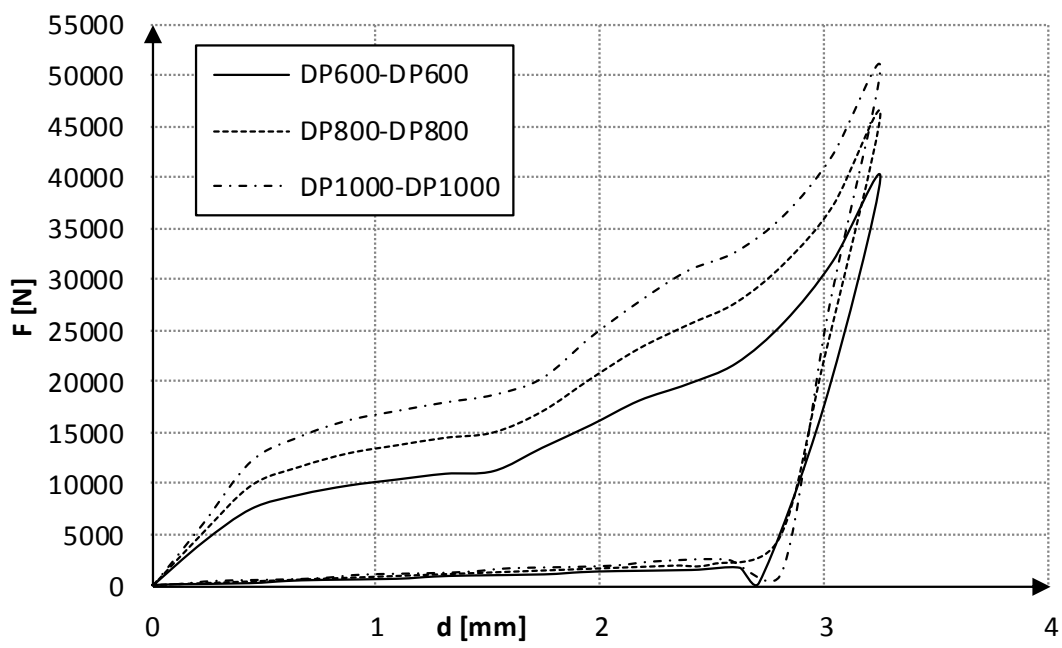

Figure 6. Comparison of the forming force-relative punching tool displacements in case of different steels 
From the results the geometrical values were determined. The values can be seen in Table 2. As it can be seen the $C$ value is decreasing with the increasing strength, the $t_{N}$ is almost constant, due to the spring back effect the $t_{B}$ value is increasing with the strength and the height of the protrusion is decreasing. The Figure 7 shows the results in graphical way. The residual bottom thickness is highly depending on the spring back effect. The spring back effect also has affected the undercut values. The neck thickness and the undercut values are important values for the joint strength prediction. The basic equations are only taken into consideration the neck thickness; which is almost constant, but according to [10] the undercut size and angle of the undercut are also important parameter. The effect of shape locking is getting higher with the increasing undercut.

Table 2. Results of the simulations

\begin{tabular}{|l|c|c|c|}
\hline $\begin{array}{l}\text { Geometrical } \\
\text { parameter }[\mathrm{mm}]\end{array}$ & DP 600 - DP 600 & DP 800- DP 800 & DP 1000 - DP 1000 \\
\hline $\mathrm{C}$ & 0.154 & 0.119 & 0.101 \\
\hline $\mathrm{t}_{\mathrm{N}}$ & 0.218 & 0.216 & 0.211 \\
\hline $\mathrm{t}_{\mathrm{B}}$ & 0.502 & 0.571 & 0.619 \\
\hline $\mathrm{h}$ & 1.715 & 1.635 & 1.588 \\
\hline
\end{tabular}

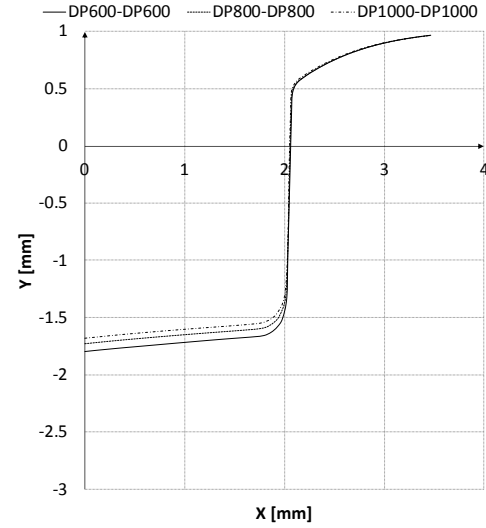

Spring back effect on punch side

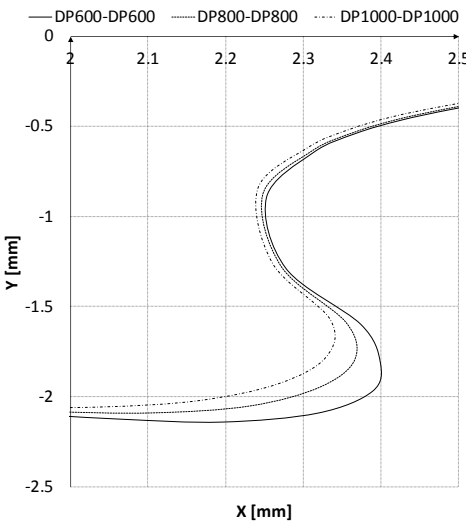

Undercut (C) sizes

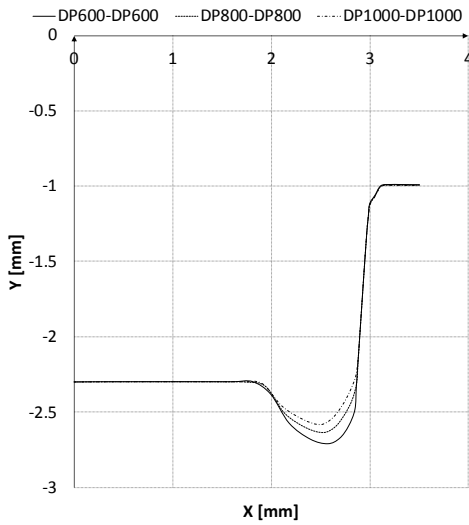

Height of the protrusion

Figure 7. Results of the simulations

From the results relationships can be derived (Figure 8). The $C$ and $t_{B}$ values according to the simulations are linear function of the $\mathrm{Rm}$. The $t_{\mathrm{N}}$ is almost constant. The $\mathrm{h}$ value is a quadratic function of the ultimate strength. The $\mathrm{R}^{2}$ values are close to 1 , which means the regression function has a good fit to the results. The derived equations can be used to predict the geometrical values of other type of DP steels. 


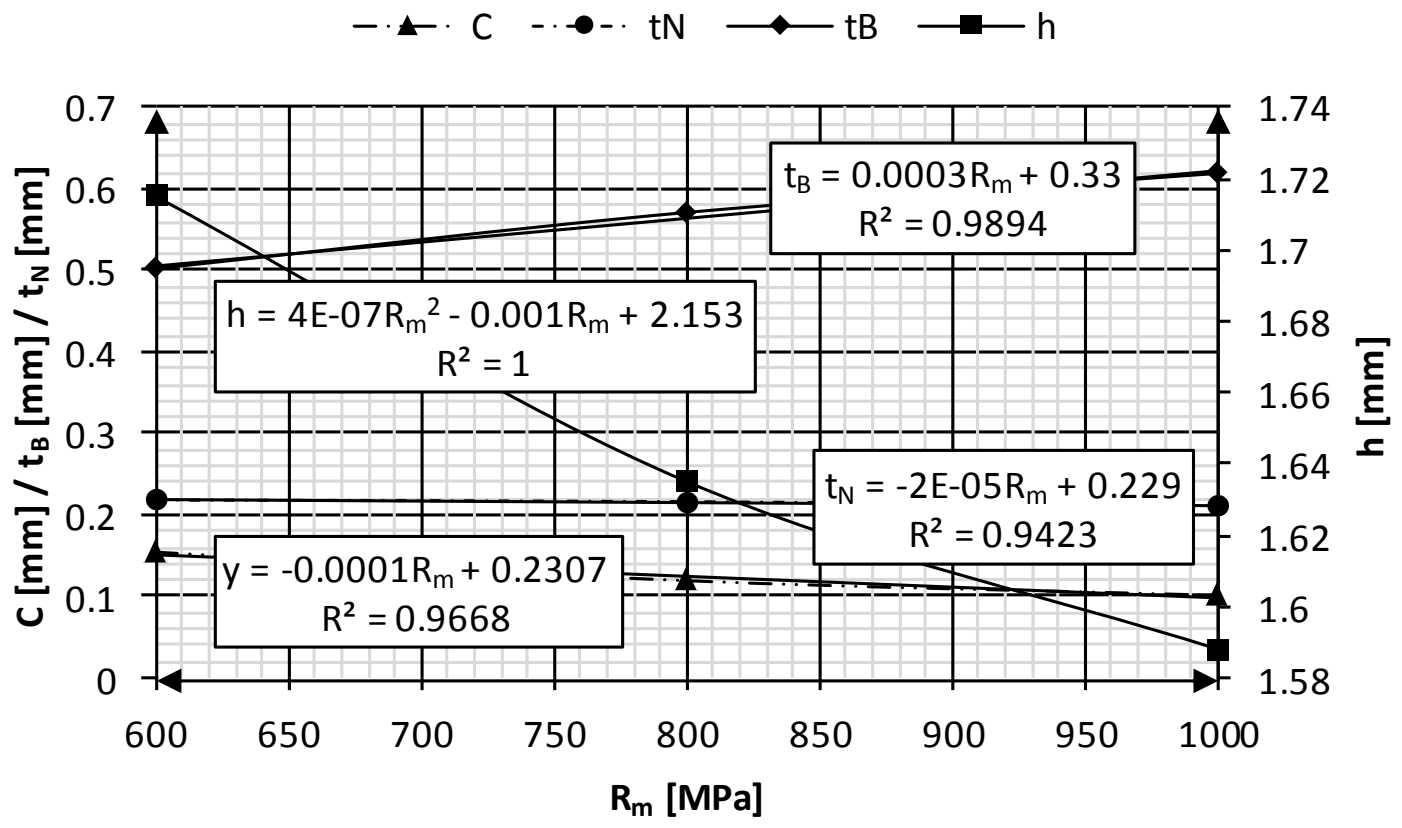

Figure 8. Relationship between the UTS and geometrical properties

\section{CONCLUSIONS}

Different strength DP steels were analysed by a 2D asymmetrical FEA model. From the results the geometrical properties of the clinched joints were determined. The article provides some equations to predict geometrical parameters of DP steels. From the predicted values with analytical formulas the strength of the joints can be predicted also. Further investigations are needed to apply the formulas to different types of steel and tests are also needed to validate the results.

\section{References}

[1] M. Tisza - G. Gaszton - A. Kiss - P. Z. Kovács - Zs. Lukács (2014) Alakítható nagyszilárdságú lemezanyagok klincs kötése. Multidiszciplináris tudományok. 4 (1) pp. 49-58.

[2] P. Z. Kovács - M. Tisza (2016) Klincs kötés technológiai paramétereinek vizsgálata, végeselemes modellezésel. Anyagmérnöki Tudományok. 39 (1) pp. 7-18.

[3] G. Béres - J. Danyi - F. Végvári (2015) Clinching of steel sheets used in automotive industry. In: Nicolae Balc (ed.) Modern Technologies in Manufacturing. 808 pp. 75-79.

[4] T. Sadowski - T. Balawender - P. Golewski (2015) Technological aspects of manufacturing and numerical modelling of clinch-adhesive joints, Springer.

[5] L. Kascák - E. Spisák (2012) Clinching as a non-standard method for joining materials of dissimilar properties. Zeszyty naukowe politechniki rzeszowskiej. Nr. 284. Mechanika z. 84. pp. 31-41.

[6] G. Béres - Z. Weltsch - Zs. Lukács - M. Tisza (2018) Prediction of stress- and strain-based forming limits of automotive thin sheets by numerical, theoretical and experimental methods. AIP Conference Proceedings 1960, 160002.doi: 10.1063/1.5035028

[7] ANSYS WB 18.2 User's guide 
International Journal of Engineering and Management Sciences (IJEMS) Vol. 4. (2019). No. 1

DOI: 10.21791/IJEMS.2019.1.42.

[8] Y. Tan - 0. Han - F. Du (2005) Process Monitoring Method with Window Technique for Clinch Jointing. ISIJ International. 45 (5) pp. 723-729

[9] S. Coppieters - S. Cooreman - H. Sol -D. Debruyne (2011) Reproducing the experimental strength of clinched connections with finite element methods. International Journal of Material Forming. 4 (4) p. 429.

[10] S. Coppieters (2012) Experimental and numerical study of clinched connections. PhD dissertation, KU Leuven. 